\title{
Novel method of polymer/low-melting-point metal alloy/light metal fiber composite fabrication
}

\author{
J. Park, K. S. Shin* \\ Magnesium Technology Innovation Center, Department of Materials Science and Engineering, Seoul National University, \\ 1 Gwanak-ro, Gwanak-gu, Seoul 08826, Republic of Korea
}

Received 16 November 2015; accepted in revised form 14 January 2016

\begin{abstract}
A novel method of polymer/low-melting-point metal alloy (LMA)/light metal fiber composite fabrication is proposed to solve problems of polymer/metal composites. The first step is mixing light metal particles with LMA at a temperature above the melting point of the LMA. The second step is cold extrusion of the LMA/light metal particles to fabricate LMA/light metal fibers. Thus, the LMA/light metal fibers with a density of $\sim 4.5 \mathrm{~g} / \mathrm{cm}^{3}$ were obtained. The last step is compounding a polymer with the LMA/light metal fibers at the processing temperature of the polymer above the melting points of the LMA. The effects of the length and the cross-sectional shape of light metal fiber on the morphology of the LMA/light metal fibers in the polymer matrix were studied, as were electrical conductivities and mechanical properties of the composites. As the length and/or the cross-sectional aspect ratio of the fibers was increased, the domains of LMA/light metal fibers formed more networks so that the electrical conductivity increased, and specific surface area of the domains increased so that notched Izod impact strength was improved. Thus, the polymer/LMA/light metal fiber composites were fabricated without degrading processability even at $60 \mathrm{vol} \%$ loading and the electrical conductivities over $10^{3} \mathrm{~S} / \mathrm{cm}$ were achieved.
\end{abstract}

Keywords: polymer composites, low-melting-point metal alloy, light metal fiber, electrical conductivity

\section{Introduction}

Electrically conductive polymer composites have drawn a lot of attentions of scientists and engineers due to their applications in various areas, such as electronic components, energy storage devices, electromagnetic interference shielding, antistatic materials, and sensors [1-3]. A traditional approach in fabrication of such a composite material is addition of electrically conductive fillers into insulating polymer to incorporate two complementary properties of electrical conductivity and processability. For example, carbon fillers such as graphite, carbon black and carbon fibers are commercially added to the insulating polymers [4-8]. They have advantages of low density and good conductivity; however, the addition of a high amount of carbon fillers for producing conductivity causes increase of viscosity resulting in degradation of processability. Carbon nanotube is one of promising alternatives. Small amounts of addition can enhance conductivity significantly due to its high aspect ratio with nanometer thick diameter [9-10]. However, it still has limitations of high cost and poor dispersibility in the polymer matrix due to van der Waals and Coulomb attractions.

Electrically conductive metal fillers can also be used as conductive filler in polymer composites, such as magnesium, aluminum, nickel, copper, silver, stainless steel and etc. [11-13]. Typically, inclusion of metal fillers increases the overall weight of composites due to their high densities when the same volume of fillers are added. Also large amounts of addition yield poor processability. Exceptionally, magnesium and aluminum are known for light-

\footnotetext{
*Corresponding author, e-mail: ksshin@snu.ac.kr

(C) BME-PT
} 
weight-metal showing relatively low density comparing to other metals. However, magnesium has a low corrosion resistance requiring additional treatment for corrosion protection [14]. In the case of aluminum, a dense oxidation layer formed on the surface increases the electrical resistivity of the composite [15].

An interesting approach was proposed to maintain processability at high filler loading by applying a low-melting-point metal alloy (LMA) by Zhang et al. [16]. Since LMA melts at the processing temperature of polymer, it does not increase viscosity of the composite due to the low viscosity of molten LMA. However, as LMA droplets were fused into large domains above melting temperature, electrical networks was not formed, resulting in a low electrical conductivity under $10^{-15} \mathrm{~S} / \mathrm{cm}$ [17]. To disperse the domains of LMA, solid metal particles were combined with LMA. Small loadings of nickel particulates prevented coalescence of the molten LMA droplets resulting in high conductivity of $\sim 10^{2} \mathrm{~S} / \mathrm{cm}$ [18]. Compounding copper fibers and LMA together with a polymer improved the dispersability of LMA and increased the filler efficiency due to large aspect ratios of LMA domains showing very high conductivity of $\sim 10^{4} \mathrm{~S} / \mathrm{cm}$ [19]. It was suggested that the solid particle acts as a mechanical aid; increasing the viscosity of the LMA droplet and slowing down the coalescence process. However, LMA/solid metal particle also has a high density, therefore the polymer composite still remains heavy.

In order to solve these problems, a polymer/LMA/ light metal fiber composite is proposed in this study. LMA was designed to be mixed with the light metal overcoming the difference of the densities of LMA and the light metal. As it encapsulates the light metal in the composite, it can play the role of blocking the increase in electrical resistance due to oxidation of the surface of the light metal. And it melts at the processing temperature of polymer and maintains processability of the composites during compounding with polymer. The light metal fiber reduces the density of the metal filler to minimize the increase in the weight of the composite. It also increases the efficiency as conductive filler by presenting a fiber form. Furthermore, it improves the dispersibility of the LMA domain by maintaining a solid state during compounding. The resulting composites exhibited high electrical conductivity and enhanced mechanical properties.

\section{Experimental}

\subsection{Materials}

Polystyrene-acrylonitrile (SAN) was used as polymer matrix and was supplied by Samsung SDI Co., Ltd. (Republic of Korea). The physical properties of SAN are as follows: The acrylonitrile content of SAN is $24.5 \mathrm{wt} \%$, the weight-average molecular weight is 140000 , the melt flow index is $2.7 \mathrm{~g} / 10 \mathrm{~min}$ in $200^{\circ} \mathrm{C} / 5.86 \mathrm{~kg}$ condition, and the notched Izod impact strength is $21.6 \mathrm{~J} / \mathrm{m}$. Aluminum (Al) was selected as the light metal particles with density of $2.7 \mathrm{~g} / \mathrm{cm}^{3}$. Al particles with spherical shape and particle size of $44 \sim 100 \mu \mathrm{m}$ were used. Sn-Zn30 alloy having tin (Sn) $70 \mathrm{wt} \%$ with zinc ( $\mathrm{Zn}) 30 \mathrm{wt} \%$ was used as LMA, which starts to melt from $230^{\circ} \mathrm{C}$.

\subsection{Preparation of composite samples}

Composite samples were prepared through the processes shown in Figure 1. Mixture of Sn-Zn30 and $\mathrm{Al}$ particles with the ratio of $40 / 60 \mathrm{vol} \%$ was stirred at $50 \mathrm{rpm}$ and $270^{\circ} \mathrm{C}$ for 10 minutes. Then, a cylindrical billet with a diameter of $76.2 \mathrm{~mm}$ and a height of $200 \mathrm{~mm}$ was molded. Afterwards, Sn-Zn30/Al fiber was fabricated using a 600 ton extruder at $170^{\circ} \mathrm{C}$ which is lower than the solidus temperature of Sn-Zn30. During the extrusions, the shape of the die was varied so that the metal fiber being generated through the extrusion process was made to have different lengths and cross-sectional shapes: circular diameter $24 \mathrm{~mm}$, extrusion ratio 10; circular diameter $15.2 \mathrm{~mm}$, extrusion ratio 25 ; and, rectangular width $26 \mathrm{~mm}$, thickness $7 \mathrm{~mm}$, extrusion ratio 25 . The extrusion ratio is defined as the starting crosssectional area divided by the cross-sectional area of the final extrusion. The processing conditions and the densities of the Sn-Zn30/Al fiber are organized in Table 1. It was found that lighter metal fillers $\left(\sim 4.5 \mathrm{~g} / \mathrm{cm}^{3}\right)$ were fabricated than typical metal fillers $\left(7-9 \mathrm{~g} / \mathrm{cm}^{3}\right)$. Figure 2 shows that $\mathrm{Al}$ fibers were elongated and thinned according to the increase in the extrusion ratio. In addition, when the shape of the extrusion die was rectangular, the width of the $\mathrm{Al}$ fibers increased and the thickness of the $\mathrm{Al}$ fibers decreased, in other words the Al fibers became flattened. From these results, it can be implied that the length of the $\mathrm{Al}$ fiber increases with increasing the extrusion ratio and the cross-sectional aspect ratio of the $\mathrm{Al}$ fiber increases when a rectangular die is used. Subsequently, Sn-Zn30/Al fiber was compounded with SAN for 5 minutes under the conditions of 


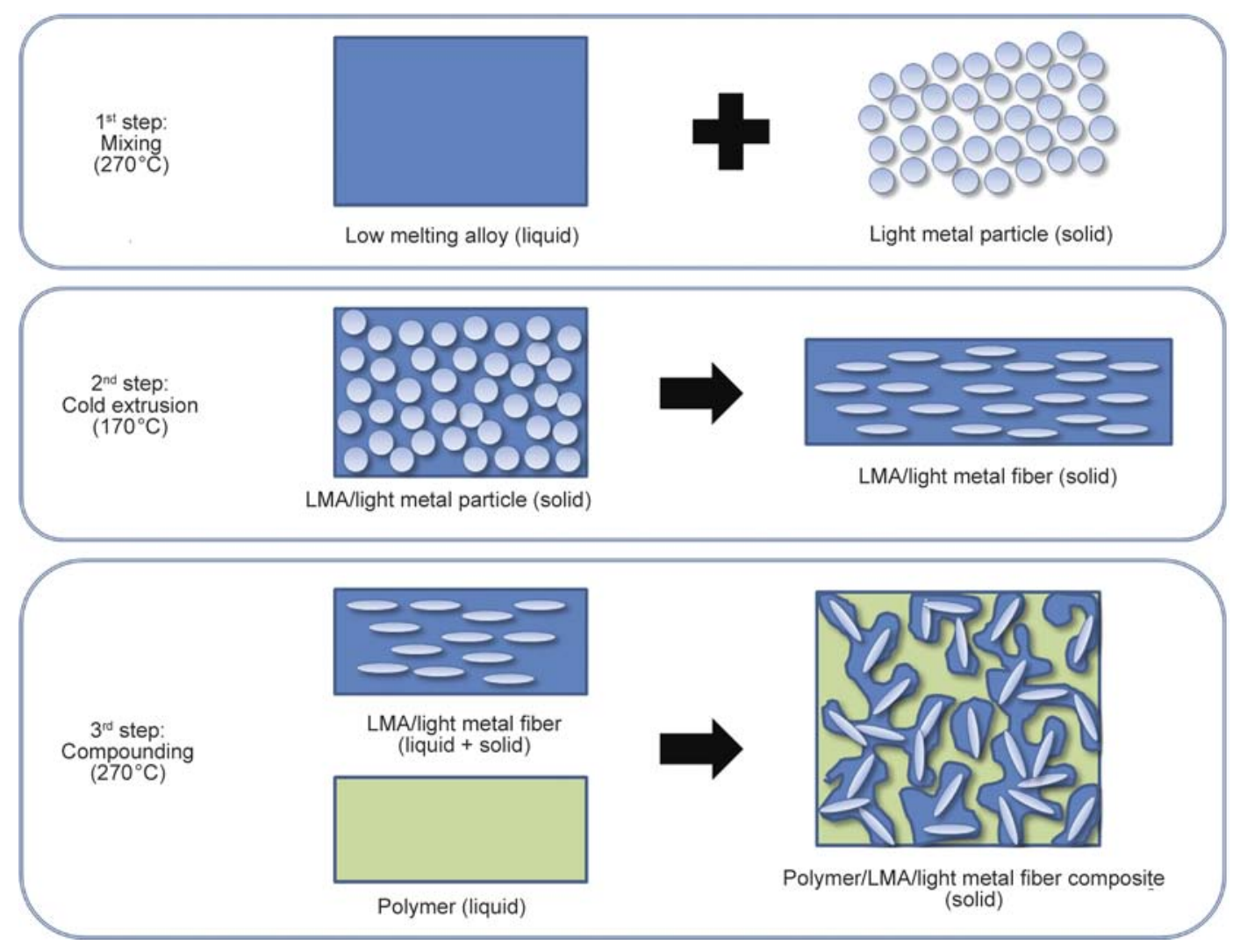

Figure 1. The technological process of preparing polymer/LMA/light metal fiber composite

Table 1. Processing conditions and densities of the metal fillers prepared

\begin{tabular}{|c|c|c|c|}
\hline $\begin{array}{c}\text { Sn-Zn30/Al } \\
\text { fiber code }\end{array}$ & Die shape & $\begin{array}{c}\text { Extrusion } \\
\text { ratio }\end{array}$ & $\begin{array}{l}\text { Density } \\
{\left[\mathrm{g} / \mathrm{cm}^{3}\right]}\end{array}$ \\
\hline $\mathrm{C} 10$ & Circle & 10 & 4.48 \\
\hline $\mathrm{C} 25$ & Circle & 25 & 4.54 \\
\hline R25 & Rectangular & 25 & 4.55 \\
\hline
\end{tabular}

$270^{\circ} \mathrm{C}$ at $50 \mathrm{rpm}$, using an internal mixer (HAAKE Polylab QC, Thermo Fischer Scientific, USA) with roller rotors. Samples were prepared varying the content of Sn-Zn30/Al fiber of 20, 40, and $60 \mathrm{vol} \%$, respectively. And in order to see the effects of LMA on the processability, for comparative evaluation, $\mathrm{Al}$ particles 20, 40, and 60 vol\% was compounded with SAN under the same conditions. Through hot pressing, composites and pure SAN (without fillers) were made into a $150 \mathrm{~mm} \times 150 \mathrm{~mm} \times 3.2 \mathrm{~mm}$ plate, and from that, specimens were produced that had a standard dimension for measuring electrical properties and mechanical properties.

\subsection{Measurements}

The morphology of Sn-Zn30/Al fiber in SAN matrix was observed using field emission scanning electron microscopy (FE-SEM, SU-70, Hitachi, Japan) with energy dispersive spectroscopy (EDS, Hariba, Japan).
The max torque was measured as the maximum value of torque on the rotors of the internal mixer during the compounding of each sample using the HAAKE Polysoft software package. For samples with an electrical conductivity higher than $10^{-7} \mathrm{~S} / \mathrm{cm}$, the electrical conductivity was measured by a fourpoint probe method at room temperature. The dimensions of the sample for electrical conductivity measurements were $60 \mathrm{~mm} \times 12.7 \mathrm{~mm} \times 3.2 \mathrm{~mm}$. A constant current was applied using a source meter $(2400$, Keithley, USA) to the outer probes of the four contacts, and the corresponding voltage was measured between inner probes using a nanovolt meter (2182, Keithley, USA) as shown in Figure 3. For samples with an electrical conductivity lower than $10^{-7} \mathrm{~S} / \mathrm{cm}$, the measurements were performed by a two-point probe method using only a source meter. Density was measured according to the ASTM D792 test method using a densimeter (Toyoseki, Japan). Notched Izod impact strength was measured according to the ASTM D256 test method (DG-1B, Toyoseki, Japan). The thickness of the testing sample was about $3.2 \mathrm{~mm}$. The three-point bending flexural modulus tests were conducted according to the ASTM D790 test method (UTM 3367, Instron, USA). The crosshead speed was $1.4 \mathrm{~mm} / \mathrm{min}$ and the distance 


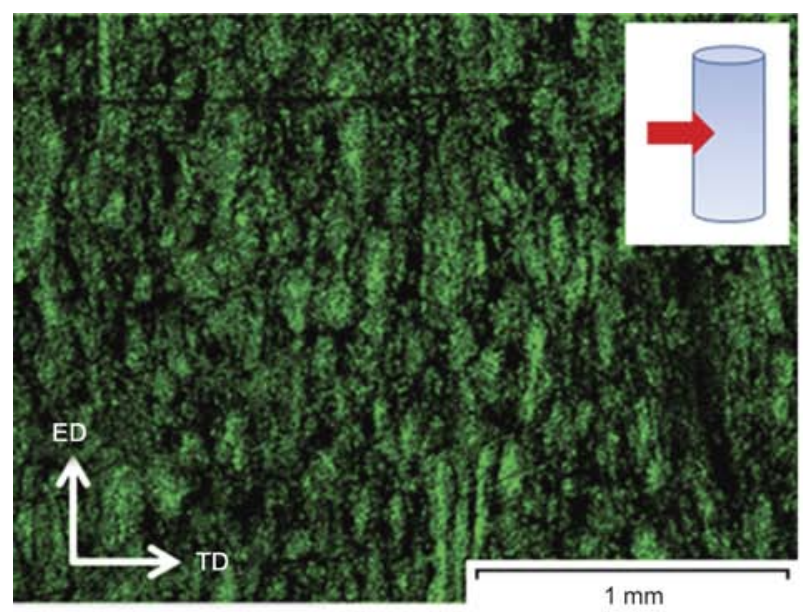

a)

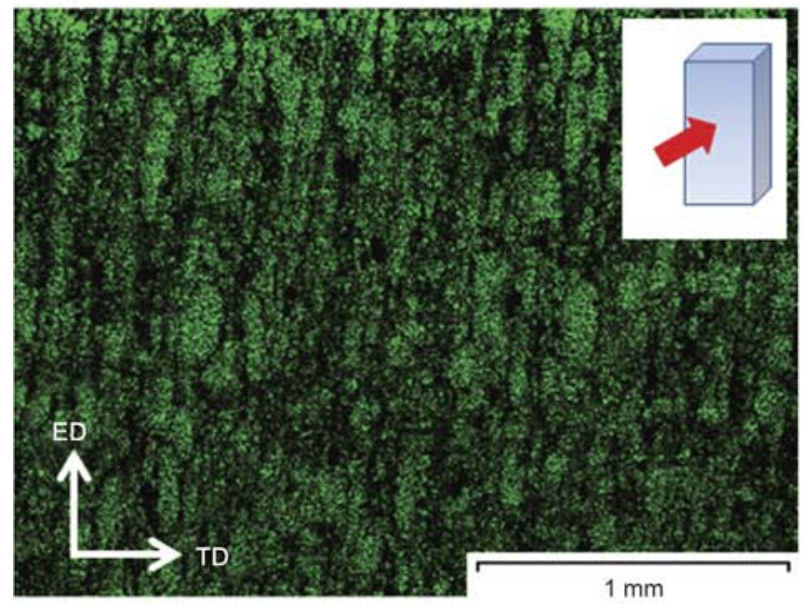

c)

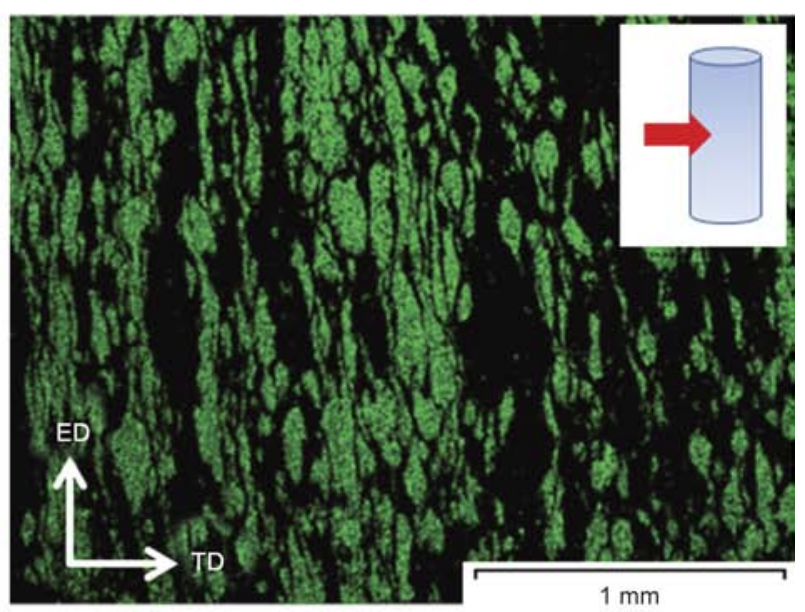

b)

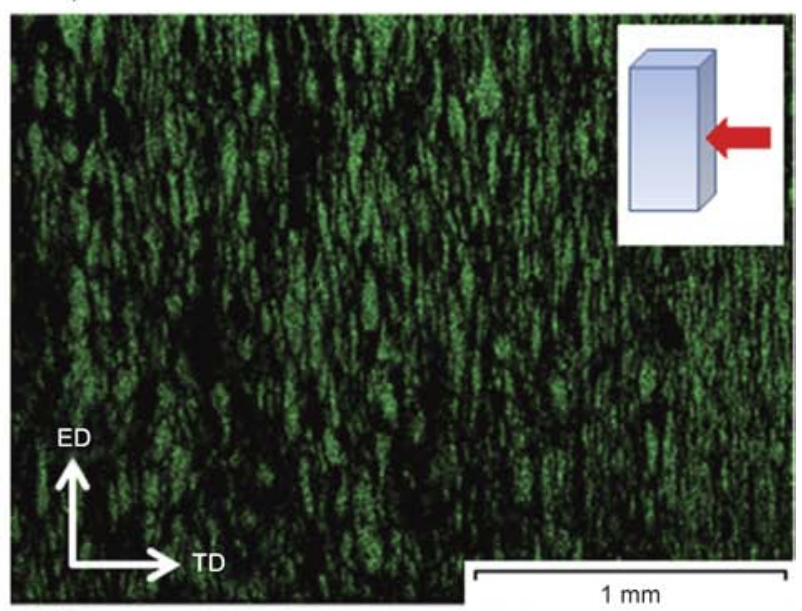

d)

Figure 2. Aluminum (green color) EDS mapping results of extruded Sn-Zn30/Al fiber (red arrow is the direction of observation in inner picture); (a) C10, (b) C25, (c-d) R25

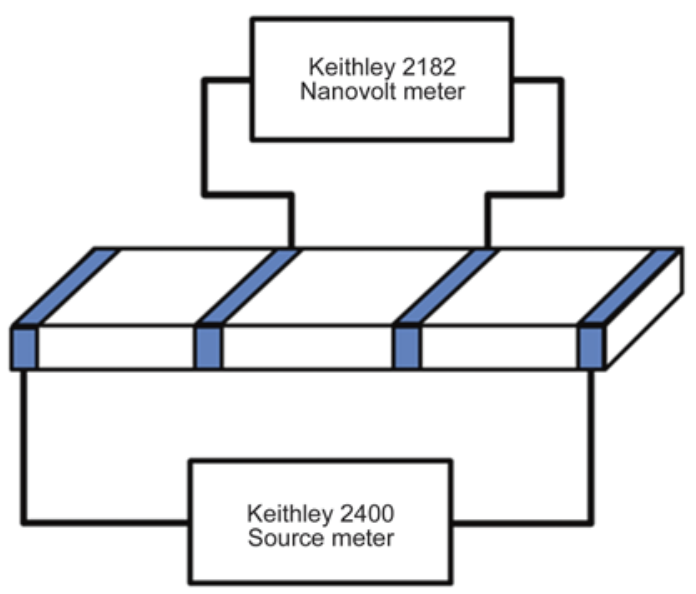

Figure 3. Electrical measurement set-up

between the two bottom points was $50 \mathrm{~mm}$. The typical dimensions of the sample beams were $70 \mathrm{~mm} \times 12.7 \mathrm{~mm} \times 3.2 \mathrm{~mm}$. The tensile tests were conducted according to the ASTM D638 test method (UTM 3367, Instron USA) at a crosshead speed of $5 \mathrm{~mm} / \mathrm{min}$. The specimens for tensile tests were type I with thickness $3.2 \mathrm{~mm}$. The electrical and mechani- cal properties were measured for 5 specimens of each composite and the average values were used for results and discussion.

\section{Results and discussion}

\subsection{Composition of LMA}

As can be seen in Figure 1, LMA becomes the matrix of LMA/light metal particles mixture in the first and second processes but act as conductive filler which is dispersed in the polymer matrix during the third process. Sn is a good candidate for LMA since it has a melting temperature of $230^{\circ} \mathrm{C}$ similar to the processing temperature of SAN. However, since the density of $\mathrm{Sn}\left(7.29 \mathrm{~g} / \mathrm{cm}^{3}\right)$ is much higher than Al, Al particles floated on top of the liquid Sn during the mixing process. The large difference in density made it very difficult to mix Al particles in liquid Sn. With regard to sedimentation, the particle velocity in the liquid under gravity would be Equation (1) [20]: 
$v=\frac{2 a^{2}\left(\rho_{\mathrm{P}}-\rho\right)}{9 \eta} g$

where $v$ is the sedimentation velocity of the particle, $\mathrm{a}$ is the radius of the particle, $\rho_{\mathrm{P}}$ is the density of the particle, $\rho$ is that of the liquid, $\eta$ is the viscosity of the liquid and $g$ is the acceleration of gravity. Assuming that a is $70 \mu \mathrm{m}, \rho_{\mathrm{P}}$ is $2.7 \mathrm{~g} / \mathrm{cm}^{3}, \rho$ is $7.29 \mathrm{~g} / \mathrm{cm}^{3}$, and $\eta$ is $1.5 \mathrm{mPa} \cdot \mathrm{s}$ [21], the sedimentation velocity of the Al particle is $-3 \mathrm{~mm} / \mathrm{s}$. As the value of the sedimentation velocity of the $\mathrm{Al}$ particle is negative, the $\mathrm{Al}$ particle is floating onto liquid $\mathrm{Sn}$. The velocity is too fast for $\mathrm{Al}$ particles to be mixed with liquid $\mathrm{Sn}$. When the density of the liquid and particle and the radius of the particle are fixed in Equation (1), the method for slowing the velocity is to increase $\eta$. However, for pure metal, it is difficult to control the viscosity since the viscosity will rapidly change during the phase transition from solid to liquid. Thus in order to increase the viscosity, a coexisting region with liquid and solid at the processing temperature of about $270{ }^{\circ} \mathrm{C}$ is needed. For a general solid-liquid suspension, the viscosity is a function of the fraction of solid. An equation which has been obtained from the empirical data can be expressed as Equation (2) [22]:

$$
\frac{\eta_{\mathrm{s}}}{\eta_{0}}=1+2.5 \Phi+10.05 \Phi^{2}+A \exp (B \Phi)
$$

where $\eta_{\mathrm{s}}$ is the viscosity of the solid-liquid suspension, $\eta_{0}$ is the viscosity of the pure liquid, $\Phi$ is the volume fraction of solid in the suspension, and $A$ and $B$ are constants which are found to be 0.00273 and 16.6 respectively. We utilized thermodynamic program Pandat ${ }^{\mathrm{TM}}$ to calculate phase fraction plot

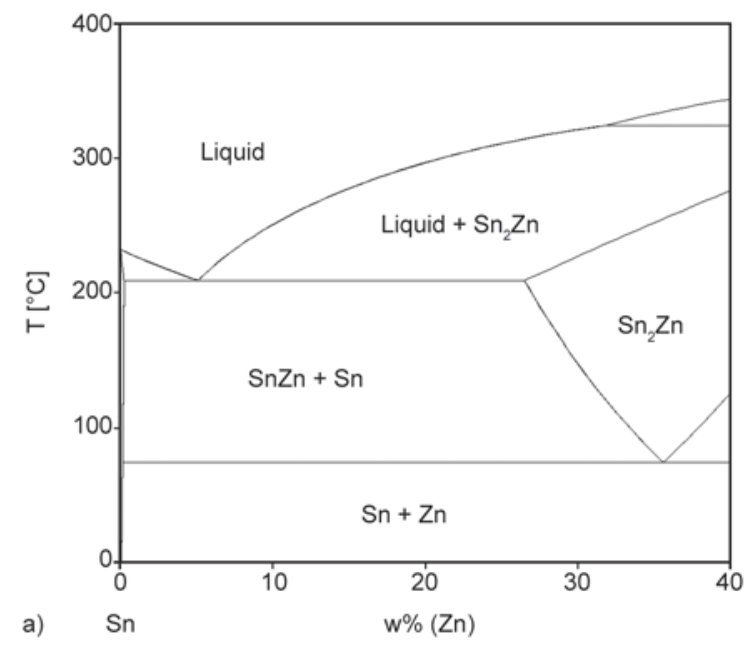

of $\mathrm{Sn}-\mathrm{Zn} 30$ alloy as shown Figure 4. Calculation results show that solidus and liquidus temperature are 230 and $320^{\circ} \mathrm{C}$, respectively. And solid volume fraction is 0.7 at $270^{\circ} \mathrm{C}$. Taking these values into Equation (2), the viscosity of suspension is calculated to be $220 \mathrm{~Pa} \cdot \mathrm{s}$. Then the velocity of the sedimentation of the $\mathrm{Al}$ particle is much decreased to $-2 \cdot 10^{-5} \mathrm{~mm} / \mathrm{s}$ obtained from Equation (1). When mixing the $\mathrm{Al}$ particles in pure tin at $270{ }^{\circ} \mathrm{C}$, they were immiscible and the Al particles became oxidized and blackened, and only the tin was solidified. However, when the Al particles were mixed into Sn-Zn30, it mixed well as shown in Figure 5.

\subsection{Max torque during compounding of SAN/Sn-Zn30/Al fiber composites}

In order to examine processability, the maximum value of torque on the rotors of the internal mixer was measured during the compounding of each sample. Figure 6 shows that the max torque increases as the filler content increased, indicating that the viscosity of the composite increases due to addition of $\mathrm{Sn}-\mathrm{Zn} 30 / \mathrm{Al}$ fiber. On the contrary, in the previous study of Zhang et al. [23], viscosity was decreased while LMA content was increasing in polystyrene/ $\mathrm{Sn}-\mathrm{Pb} 30$ (Sn $70 \mathrm{wt} \%$ and lead $(\mathrm{Pb}) 30 \mathrm{wt} \%$ ). In case of polystyrene/ $\mathrm{Sn}-\mathrm{Pb} 30$ composites, LMA was entirely liquid at the processing temperature of $190^{\circ} \mathrm{C}$. Meanwhile, in current study, Sn-Zn30 is in coexisting state of solid and liquid and Al fibers is also solid at the processing temperature of $270^{\circ} \mathrm{C}$. Therefore the viscosity of SAN/Sn-Zn30/Al fiber composites increases, when the filler content is increased. Comparing to sample of Al particles used alone, SAN/Sn-Zn30/Al fiber composites show sig-

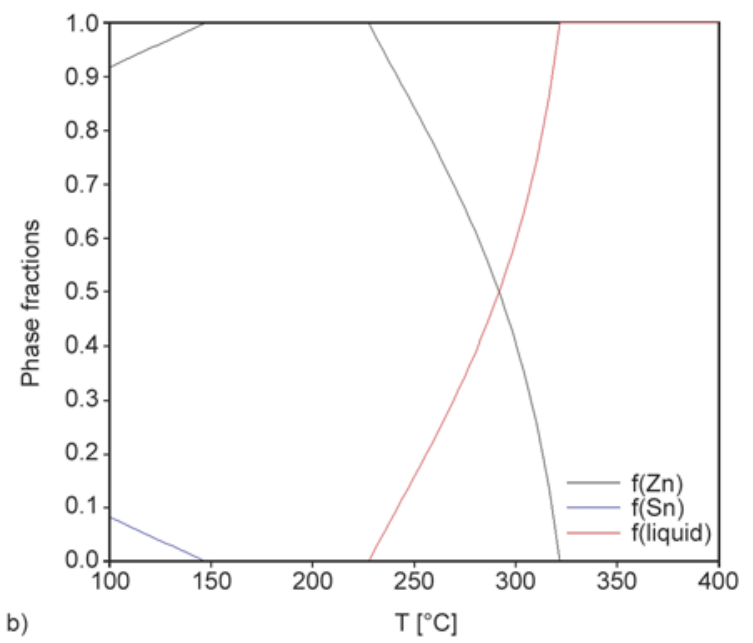

Figure 4. (a) Phase diagram of $\mathrm{Sn}-\mathrm{Zn}$, (b) phase fraction plot of $\mathrm{Sn}-\mathrm{Zn} 30$ as a function of temperature 


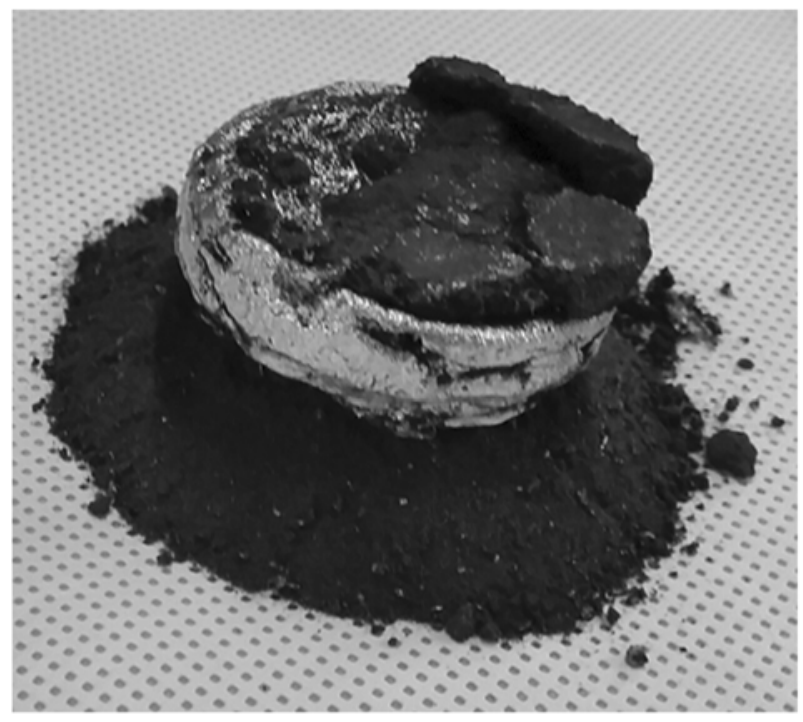

a)

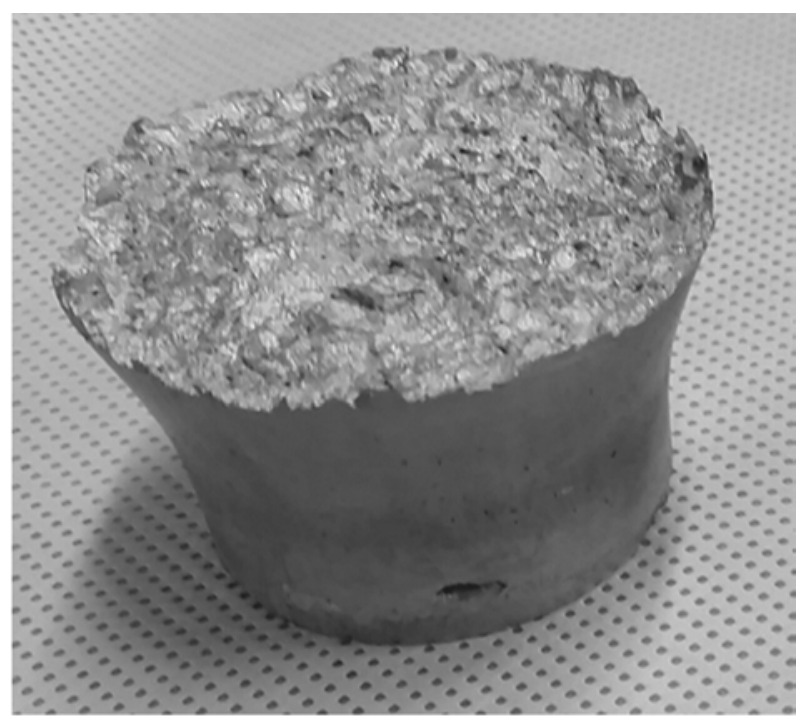

b)

Figure 5. Mixture after 10 min mixing under 50 rpm stirring; (a) pure tin and aluminum particles, (b) Sn-Zn30 and aluminum particles

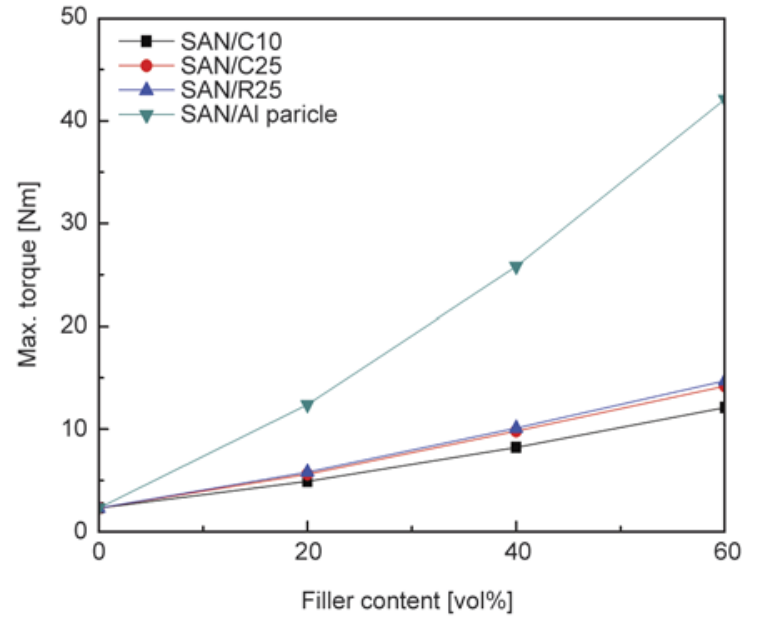

Figure 6. Max torque of the internal mixer during compounding of the SAN/Sn-Zn30/Al fiber composites

nificantly lower torque, indicating that the molten $\mathrm{Sn}-\mathrm{Zn} 30$ mitigates the shear stress applied to the solid in the filler lowering the viscosity of the filler. In case that the extrusion ratio was high, the max torque was slightly higher. We presumed that, as the length of fiber is increased, the excluded volume of the fiber is also increased, resulting in an increase of the viscosity [24].

\subsection{Morphology of $\mathrm{Sn}-\mathrm{Zn} 30 / \mathrm{Al}$ fiber in the SAN matrix}

The morphology of Sn-Zn30/Al fiber in SAN matrix was observed using EDS. The Al fibers were wrapped around by $\mathrm{Sn}$ and $\mathrm{Zn}$ and well-dispersed as can be seen in Figure 7. During cold extrusion, the oxidation layer of $\mathrm{Al}$ surface might become thin and/or be broken as Al particles were elongated. Therefore, $\mathrm{Sn}-\mathrm{Zn} 30 / \mathrm{Al}$ fiber through cold extrusion can reduce the oxidation layer of Al surface which can affect the wetting behavior. Since the surface tension of Sn-Zn30 is much greater than that of SAN, a large domain must be formed thermodynamically by aggregation. However, the dispersibility of the filler is improved because the solid Al fibers physically help the dispersion and slow the rate of aggregation with increase of the viscosity of the filler within molten Sn-Zn30 [18]. The domains of the metal filler became elongated with the increase in the extrusion ratio of the $\mathrm{Sn}-\mathrm{Zn} 30 / \mathrm{Al}$ fiber, indicating that the domain shape of the filler can be controlled by the shape of Al fiber. When polymer/metal composites were prepared using LMA alone, the domains of LMA in the polymer/LMA composite generally formed large spherical droplet due to the surface tension of LMA, therefore the efficiency as conductive filler decreased [17]. In contrast, Sn-Zn30/Al fiber system can improve the efficiency as conductive filler by increasing the length of $\mathrm{Al}$ fiber. It is believed that the efficiency as conductive filler relates to the connectivity between the domains of the filler. When the extrusion ratio increased and/or the shape of the extrusion die was rectangular, as with samples C25 and R25, the connectivity improved since the specific surface area increased as the length and/or the cross-sectional aspect ratio of the $\mathrm{Al}$ fiber increased. In addition, although the domains of the filler became larger with increasing filler content, the connectivity improved by maintaining the 


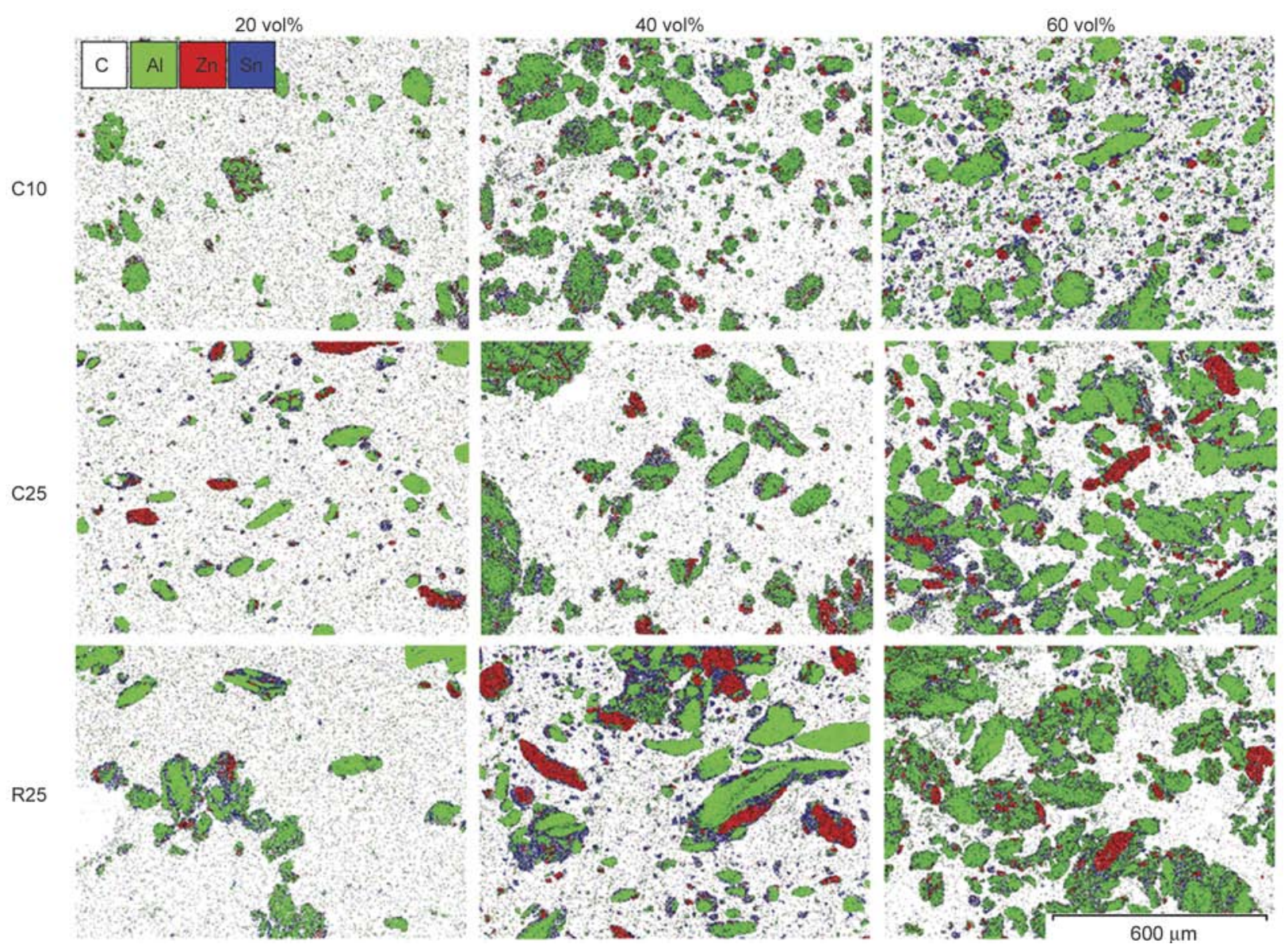

Figure 7. EDS mapping images of SAN/Sn-Zn30/Al fiber composites

elongated domains due to the Al fibers. It can be concluded that the incorporation of Al fiber is critical in the dispersion of the filler and in the improvement of the efficiency as conductive filler.

\subsection{Electrical conductivity}

Figure 7 shows that the connectivity between the domains of Sn-Zn30/Al fiber increases as the content of $\mathrm{Sn}-\mathrm{Zn} 30 / \mathrm{Al}$ fiber, the length of $\mathrm{Al}$ fiber, and the cross-sectional aspect ratio of $\mathrm{Al}$ fiber increases. It is generally believed that the conductivity of the composite derives from the formation of a conducting network by the fillers in the matrix, and the increase of conductivity paths facilitates the improvement of the composite conductivity [25]. Such formation of a conducting network would improve the electrical conductivity of SAN/Sn-Zn30/Al fiber composites. Thus, Figure 8 shows that the electrical conductivities of the composites increased with increasing the filler content. The composites with filler at $20 \mathrm{vol} \%$ resulted in low conductivities of $\sim 10^{-12} \mathrm{~S} / \mathrm{cm}$ since the conducting networks were not formed, as shown in Figure 7. From a filler content of $40 \mathrm{vol} \%$ and higher, the conductivities

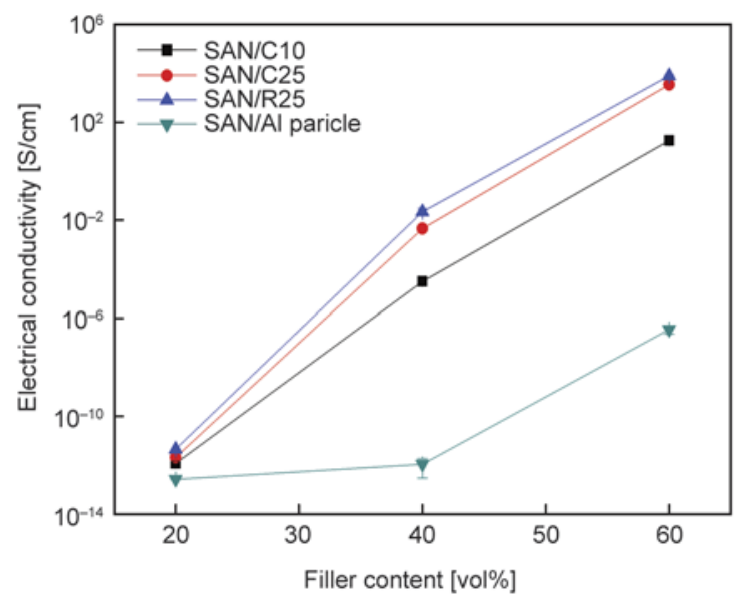

Figure 8. Electrical conductivity of SAN/LMA/Al fiber composites

increased dramatically. In addition, the electrical conductivities of SAN/C25 and R25 were higher than that of SAN/C10 at the same filler content. This indicates that as the domains are more elongated, the electrical conductivity increases due to improving the connectivity between the fillers. As the electrical conductivities of SAN/Sn-Zn30/Al fiber composites were higher than those of SAN/Al particle composites, it is implied that the oxide layer on the 
surface of Al fiber could not impede the electrical conductivity due to the encapsulation of Sn-Zn30. For SAN/R25 at 60 vol\% loading, the polymer matrix and the domains of fillers formed almost co-continuous structure as shown in Figure 8, resulting in the electrical conductivity of $7900 \mathrm{~S} / \mathrm{cm}$. This electrical conductivity is higher than that $\left(\sim 10^{2} \mathrm{~S} / \mathrm{cm}\right)$ of polymer/LMA/nickel particle at 60 vol\% loading [18], indicating that $\mathrm{Al}$ fiber is more effective than nickel particle due to the fibrous shape.

\subsection{Density and mechanical properties}

The results of density and mechanical properties were summarized in Table 2. As the density of Sn$\mathrm{Zn} 30 / \mathrm{Al}$ fiber $\left(\sim 4.5 \mathrm{~g} / \mathrm{cm}^{3}\right)$ is relatively lighter than that of other LMA fillers $\left(7-9 \mathrm{~g} / \mathrm{cm}^{3}\right)$, the density of SAN/Sn-Zn30/Al fiber composite is lighter than other polymer/LMA filler composites. While the estimated density of polymer/LMA/nickel particle composite with the filler content of $60 \mathrm{vol} \%$ is $\sim 5.6 \mathrm{~g} / \mathrm{cm}^{3}$ [18], the density of SAN/R25 with the same content is $3.14 \mathrm{~g} / \mathrm{cm}^{3}$.

The impact strength decreased slightly with the filler content of $20 \mathrm{vol} \%$, but the impact strength was enhanced with the increase of the filler content as shown in Figure 9. In addition, when the extrusion ratio was increased and the shape of the extrusion die was rectangular, the growth rate was much larger. The fractured surfaces after notched Izod testing were observed through SEM as shown in Figure 10. It can be seen that the fracture occurred at the interface of SAN and the filler. Since the interaction between SAN and the filler is weak, the filler acts as a defect and reduces the notched Izod impact strength. In other words, the interfacial energy between SAN and metal filler would be a dominant factor for the impact strength of the SAN/Sn-Zn30/Al fiber com-

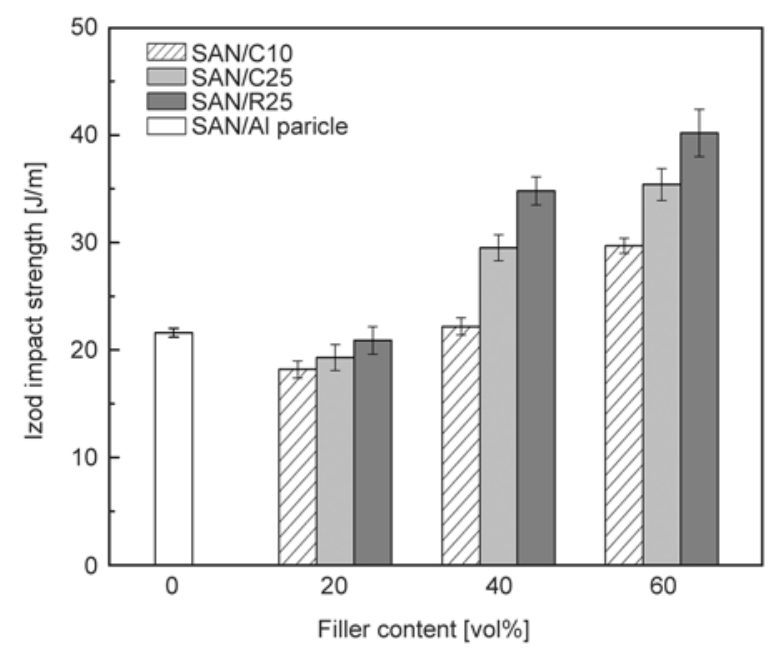

Figure 9. Notched Izod impact strength of the SAN/SnZn30/Al fiber composites

posite [26]. When the length and the cross-sectional aspect ratio of the $\mathrm{Al}$ fiber are increased, the specific surface area of the domain of the filler will be increased more than in the case of the spherical filler domain, and this can contribute to the increase in impact strength by increasing the total interfacial energy. In addition, as the filler content increases, not only the surface area of the domains of the filler increases, but the connectivity between the domains of the filler is increased, resulting in the enhancement of the impact strength.

As shown in Figures 9 and 11, the notched Izod impact strength increased from $21.6 \mathrm{~J} / \mathrm{m}$ for pure SAN to $29.7-40.2 \mathrm{~J} / \mathrm{m}$ for composites with $60 \mathrm{vol} \%$ by approximately $40-90 \%$, the flexural modulus increased from $2.11 \mathrm{GPa}$ for pure SAN to $10.1-$ $10.5 \mathrm{GPa}$ for composites with $60 \mathrm{vol} \%$ filler content by approximately $400 \%$. With regard to the filler content, the enhancement of the flexural modulus is larger than that of the notched Izod impact strength. However, in contrast to the notched Izod impact

Table 2. Density and mechanical properties of the SAN/Sn-Zn30/Al fiber composites

\begin{tabular}{|c|c|c|c|c|c|c|c|}
\hline & $\begin{array}{c}\text { Filler content } \\
\text { [vol\%] }\end{array}$ & $\begin{array}{l}\text { Density } \\
{\left[\mathrm{g} / \mathrm{cm}^{3}\right]}\end{array}$ & $\begin{array}{c}\text { Impact } \\
\text { strength } \\
{[\mathrm{J} / \mathrm{m}]}\end{array}$ & $\begin{array}{c}\text { Flexural } \\
\text { modulus } \\
\text { [GPa] }\end{array}$ & $\begin{array}{c}\text { Tensile } \\
\text { strength } \\
\text { [MPa] }\end{array}$ & $\begin{array}{c}\text { Tensile } \\
\text { modulus } \\
\text { [GPa] }\end{array}$ & $\begin{array}{c}\text { Elongation at } \\
\text { break } \\
{[\%]} \\
\end{array}$ \\
\hline pure SAN & 0 & 1.08 & 21.6 & 2.11 & 59.7 & 2.45 & 2.93 \\
\hline \multirow{3}{*}{ SAN/C10 } & 20 & 1.75 & 18.2 & 2.88 & 39.6 & 3.32 & 1.22 \\
\hline & 40 & 2.41 & 22.2 & 4.60 & 46.9 & 5.26 & 0.89 \\
\hline & 60 & 3.10 & 29.7 & 10.50 & 86.1 & 10.80 & 0.81 \\
\hline \multirow{3}{*}{ SAN/C25 } & 20 & 1.76 & 19.3 & 2.89 & 40.1 & 3.34 & 1.21 \\
\hline & 40 & 2.43 & 29.5 & 4.82 & 50.9 & 5.37 & 0.96 \\
\hline & 60 & 3.13 & 35.4 & 10.10 & 96.5 & 10.70 & 0.91 \\
\hline \multirow{3}{*}{ SAN/R25 } & 20 & 1.76 & 20.9 & 2.84 & 41.3 & 3.35 & 1.25 \\
\hline & 40 & 2.43 & 34.8 & 4.75 & 52.2 & 5.34 & 0.98 \\
\hline & 60 & 3.14 & 40.2 & 10.40 & 98.1 & 10.60 & 0.95 \\
\hline
\end{tabular}




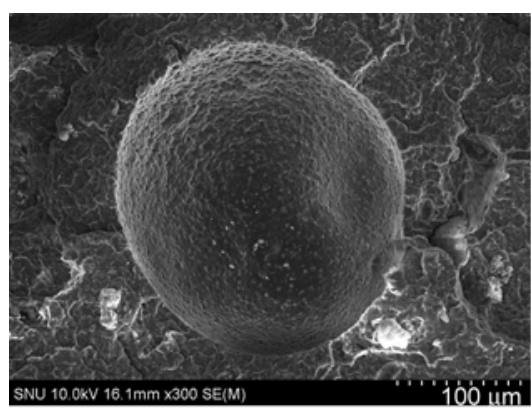

a)

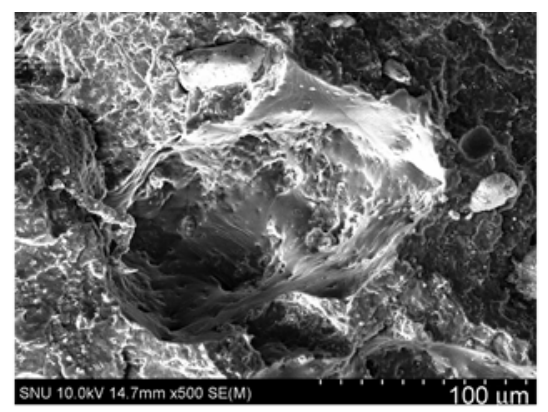

b)

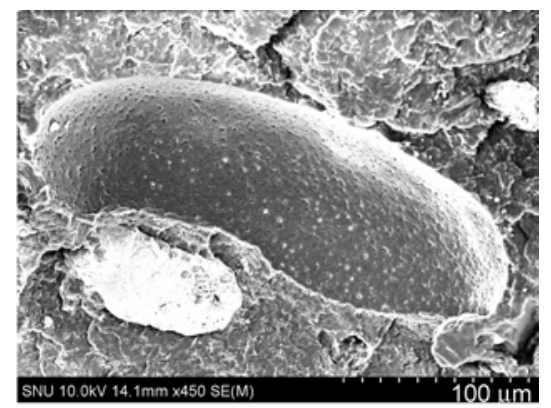

c)

Figure 10. SEM images of the factured surfaces of composites with the metal filler content of 20 vol\%; (a) C10, (b) C25, (c) R25

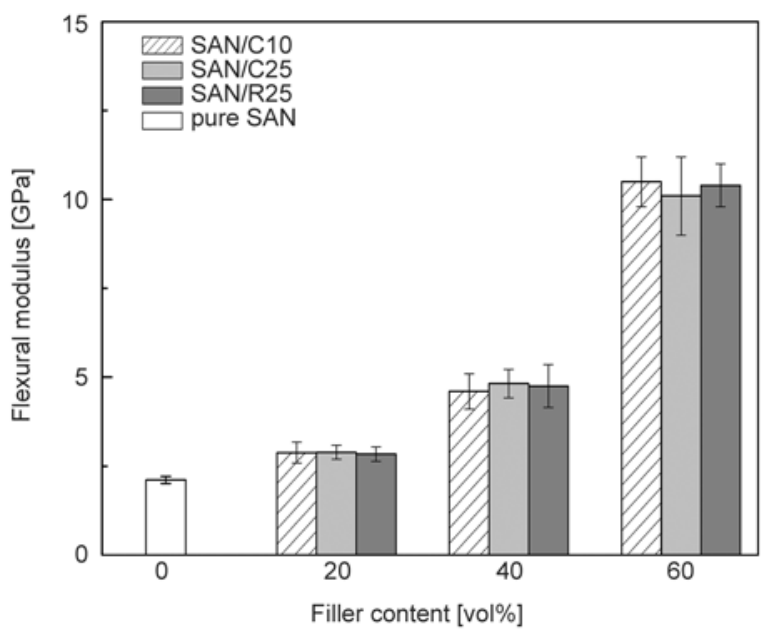

Figure 11. Flexural modulus of the SAN/Sn-Zn30/Al fiber composites

strength, its growth rate was not as high even with the increase in the extrusion ratio, indicating that the flexural modulus follows the rule of mixture being influenced by the contents of the filler rather than the shape of the filler [27].

The tensile strength decreased with the filler content of $20 \mathrm{vol} \%$, but the impact strength was enhanced

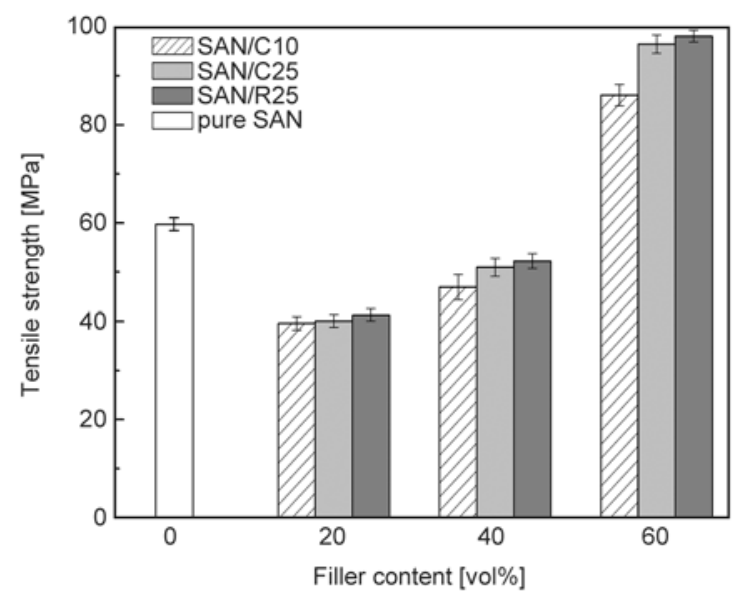

Figure 12. Tensile strength of the SAN/Sn-Zn30/Al fiber composites with the increase of the filler content as shown in Figure 12 and Table 2. Although the tensile modulus increased as the filler content increased, the elongation decreased considerably due to addition of the filler. As a result the tensile strengths of the composites with the filler contents of 20, $40 \mathrm{vol} \%$ were lower than that of pure SAN. However, as the increase in the tensile modulus was larger than the decrease in the elongation at the filler content of $60 \mathrm{vol} \%$, the tensile strengths of the composites with the filler content of $60 \mathrm{vol} \%$ were higher than that of pure SAN.

\section{Conclusions}

We have established a novel method of fabricating metal filler with lightness and excellent electrical conductivity that can be compounded with polymer without degrading the processability. Using SnZn30 having a coexisting region with liquid and solid at a mixing temperature, $\mathrm{Sn}-\mathrm{Zn} 30$ and $\mathrm{Al}$ particles could be mixed. Through the cold extrusion of Sn-Zn30/Al particles, Sn-Zn30/Al fiber was fabricated to increase the efficiency as conductive filler. When Al particles were elongated, the oxidation layer of Al surface could become thin and/or be broken, resulting in an improvement of the wettability of Sn$\mathrm{Zn} 30$ and Al fiber. The results of EDS show that the light metal fibers were wrapped around by Sn-Zn30 after compounding Sn-Zn30/Al fiber with polymer. When Sn-Zn30/Al fiber was compounded with polymer, the molten $\mathrm{Sn}-\mathrm{Zn} 30$ maintained the processability, and the dispersibility of Sn-Zn30/Al fiber was improved due to the solid $\mathrm{Al}$ fiber. As the shape of $\mathrm{Al}$ fiber was controlled by varying the extrusion conditions, it was found that electrical conductivity and the notched Izod impact strength are improved when the length and the cross-sectional aspect ratio of $\mathrm{Al}$ fiber increases. Furthermore, as Sn-Zn30/Al fiber $\left(\sim 4.5 \mathrm{~g} / \mathrm{cm}^{3}\right)$ is relatively lighter than other LMA 
fillers $\left(7-9 \mathrm{~g} / \mathrm{cm}^{3}\right)$, the SAN/Sn-Zn30/Al fiber composite $\left(3.14 \mathrm{~g} / \mathrm{cm}^{3}\right.$ at filler content of $\left.60 \mathrm{vol} \%\right)$ is lighter than other polymer/LMA filler composites $\left(5-6 \mathrm{~g} / \mathrm{cm}^{3}\right.$ at same content). We anticipate that with these characteristics this polymer/LMA/light metal fiber composite can be utilized in a variety of industrial applications.

\section{Acknowledgements}

This work was financially supported by the World Premier Materials (WPM) Program funded by the Korean Ministry of Knowledge Economy and the National Research Foundation of Korea (NRF) grant funded by the Korea government (MEST) (No. 2015006795) through the Research Institute of Advanced Materials and Magnesium Technology Innovation Center. The authors appreciate the financial support from the Samsung SDI Co., Ltd. to make this work possible.

\section{References}

[1] Chung D. D. L.: Electromagnetic interference shielding effectiveness of carbon materials. Carbon, 39, 279285 (2001).

DOI: 10.1016/S0008-6223(00)00184-6

[2] Zhang Q-H., Chen D-J.: Percolation threshold and morphology of composites of conducting carbon black/ polypropylene/EVA. Journal of Materials Science, 39, 1751-1757 (2004).

DOI: 10.1023/B:JMSC.0000016180.42896.0f

[3] Li C., Thostenson E. T., Chou T-W.: Sensors and actuators based on carbon nanotubes and their composites: A review. Composites Science and Technology, 68, 1227-1249 (2008).

DOI: 10.1016/j.compscitech.2008.01.006

[4] Balberg I.: A comprehensive picture of the electrical phenomena in carbon black-polymer composites. Carbon, 40, 139-143 (2002). DOI: $10.1016 / \mathrm{S} 0008-6223(01) 00164-6$

[5] Heo S. I., Yun J. C., Oh K. S., Han K. S.: Influence of particle size and shape on electrical and mechanical properties of graphite reinforced conductive polymer composites for the bipolar plate of PEM fuel cells. Advanced Composite Materials, 15, 115-126 (2006). DOI: $10.1163 / 156855106776829356$

[6] Chung D. D. L.: Comparison of submicron-diameter carbon filaments and conventional carbon fibers as fillers in composite materials. Carbon, 39, 1119-1125 (2001). DOI: $10.1016 / \mathrm{S} 0008-6223(00) 00314-6$

[7] Dani A., Ogale A. A.: Electrical percolation behavior of short-fiber composites: Experimental characterization and modeling. Composites Science and Technology, 56, 911-920 (1996). DOI: 10.1016/0266-3538(96)00054-1
[8] Deng S. H., Zhao J. J., Lin Q. F., Fan C. J., Zhou X. D.: Formation of interfacial network structure via photocrosslinking in carbon fiber/epoxy composites. Express Polymer Letters, 8, 505-516 (2014).

DOI: 10.3144 /expresspolymlett.2014.54

[9] Bauhofer W., Kovacs J. Z.: A review and analysis of electrical percolation in carbon nanotube polymer composites. Composites Science and Technology, 69, 14861498 (2009).

DOI: 10.1016/j.compscitech.2008.06.018

[10] Auilar J. O., Bautista-Quijano J. R., Avilés F.: Influence of carbon nanotube clustering on the electrical conductivity of polymer composite films. Express Polymer Letters, 4, 292-299 (2010).

DOI: $10.3144 /$ expresspolymlett.2010.37

[11] Bigg D. M.: Mechanical, thermal, and electrical properties of metal fiber-filled polymer composites. Polymer Engineering and Science, 19, 1188-1192 (1979). DOI: $10.1002 /$ pen.760191610

[12] Li Y-J., Xu M., Feng J-Q., Dang Z-M.: Dielectric behavior of a metal-polymer composite with low percolation threshold. Applied Physics Letters, 89, 072902/1072902/3 (2006).

DOI: $10.1063 / 1.2337157$

[13] Bloor D., Donnelly K., Hands P. J., Laughlin P., Lussey D.: A metal-polymer composite with unusual properties. Journal of physics D: Applied Physics, 38, 28512860 (2005).

DOI: $10.1088 / 0022-3727 / 38 / 16 / 018$

[14] Kumar A. M., Kwon S. H., Jung H. C., Shin K. S.: Corrosion protection performance of single and dual plasma electrolytic oxidation (PEO) coating for aerospace applications. Materials Chemistry and Physics, 149-150, 480-486 (2015). DOI: $10.1016 / \mathrm{j}$. matchemphys.2014.10.049

[15] Song J-H., Nam K-S., Moon J-I., Choi Y-J., Lim D-Y.: Influence of the duty cycle on structural and mechanical properties of oxide layers on Al-1050 by a plasma electrolytic oxidation process. Metals and Materials International, 20, 451-458 (2014).

DOI: $10.1007 / \mathrm{s} 12540-014-3025-2$

[16] Zhang X., Pan Y., Shen L., Yi X.: Novel low melting point alloy-loaded polymer composite. II. Resistivitytemperature behavior. Journal of Applied Polymer Science, 77, 756-763 (2000).

DOI: $10.1002 /($ SICI $) 1097-4628(20000725) 77: 4<756:$ : AID-APP7>3.0.CO;2-Y

[17] Zhang X., Pan Y., Shen L., Zheng Q., Yi X.: A novel low-melting-point alloy-loaded polymer composite. I. Effect of processing temperature on the electrical properties and morphology. Journal of Applied Polymer Science, 77, 1044-1050 (2000).

DOI: $10.1002 / 1097-4628(20000801) 77: 5<1044:: A I D-$ APP11>3.0.CO;2-D 
[18] Mrozek R. A., Cole P. J., Mondy L. A., Rao R. R., Bieg L. F., Lenhart J. L.: Highly conductive, melt processable polymer composites based on nickel and low melting eutectic metal. Polymer, 51, 2954-2958 (2010). DOI: $10.1016 /$ j.polymer.2010.04.067

[19] Michaeli W., Pfefferkorn T. G.: Electrically conductive thermoplastic/metal hybrid materials for direct manufacturing of electronic components. Polymer Engineering and Science, 49, 1511-1524 (2009).

DOI: $10.1002 /$ pen.21374

[20] Batchelor G. K.: Sedimentation in a dilute dispersion of spheres. Journal of Fluid Mechanics, 52, 245-268 (1972).

DOI: $10.1017 / \mathrm{S} 0022112072001399$

[21] Battezzati L., Greer A. L.: The viscosity of liquid metals and alloys. Acta Metallurgica, 37, 1791-1802 (1989). DOI: 10.1016/0001-6160(89)90064-3

[22] Thomas D. G.: Transport characteristics of suspension: VIII. A note on the viscosity of newtonian suspensions of uniform spherical particles. Journal of Colloid Science, 20, 267-277 (1965). DOI: 10.1016/0095-8522(65)90016-4

[23] Zhang X., Pan Y., Cheng J., Yi X.: The influence of lowmelting-point alloy on the rheological properties of a polystyrene melt. Journal of Materials Science, 35, 4573-4581 (2000).

DOI: $10.1023 / \mathrm{A}: 1004845426786$
[24] Starý Z., Krückel J., Weck C., Schubert D. W.: Rheology and conductivity of carbon fibre composites with defined fibre lengths. Composites Science and Technology, 85, 58-64 (2013).

DOI: 10.1016/j.compscitech.2013.06.006

[25] Allaoui A., Bai S., Cheng H. M., Bai J. B.: Mechanical and electrical properties of a MWNT/epoxy composite. Composites Science and Technology, 62, 1993-1998 (2002).

DOI: $10.1016 / \mathrm{S} 0266-3538(02) 00129-\mathrm{X}$

[26] Wetzel B., Haupert F., Friedrich K., Zhang M. Q., Rong M. Z.: Impact and wear resistance of polymer nanocomposites at low filler content. Polymer Engineering and Science, 42, 1919-1927 (2002).

DOI: $10.1002 /$ pen. 11084

[27] Thomason J. L., Vlug M. A.: Influence of fibre length and concentration on the properties of glass fibre-reinforced polypropylene: 1 . Tensile and flexural modulus. Composites Part A: Applied Science and Manufacturing, 27, 447-484 (1996).

DOI: $10.1016 / 1359-835 X(95) 00065-\mathrm{A}$ 